\title{
Imipramine-Provoked Paradoxical Pheochromocytoma Crisis: A Case of Cardiogenic Shock
}

\author{
KEVIN L. FERGUSON, MD
}

\begin{abstract}
The dramatic presentation of pheochromocytoma in crisis is uncommon and is classically associated with a state of hemodynamic and sympathelic hyperactivity. The case of a 35-year-old man with an occult pheochromocytoma presenting with hypotension and cardiogenic shock shortly after beginning imipramine therapy is presented. Retrospectively, there was a history of emergency department, inpatient, and outpatient evaluation of symptoms likely to be related to an occult pheochromocytoma. He presented with hypotension refractory to fluids and inotropes and in severe respiratory distress. The early differential diagnosis was extensive including acute myocardial infarction, pneumonia with sepsis, and toxic ingestion. Shortly after admission the patient's occult pheochromocytoma was discovered and subsequently specific therapy was initiated. The patient's symptoms resolved after surgical resection of the tumor, and he was ultimalely discharged without signs of congestive heart failure. The clinical pathophysiology of cardiomyopathy secondary to pheochromocytoma, and possible mechanisms of pharmacological interactions with tricyclic antidepressants are discussed. (Am J Emerg Med 1994;12:190-192. Copyright (C) 1994 by W.B. Saunders Company)
\end{abstract}

Pheochromocytomas are tumors that can secrete large amounts of catecholamines. Pheochromocytoma crisis is a syndrome of catecholamine excess that classically presents with tachycardia, diaphoresis, headache, and hypertension. Congestive heart failure is an atypical presentation and is probably caused by catecholamine-induced cardiomyopathy. This type of cardiomyopathy is well described in the literature and may be either dilated or hypertrophied. It typically reverses when the source of excess catecholamines is removed.

There have been only three reports of imipramine-induced pheochromocytoma crisis in the past 25 years. ${ }^{1.2,3}$ Imipramine blocks the reuptake of norepinephrine, thereby increasing amount of neurotransmitter in the synaptic cleft and potentiating the presser effects of norepinephrine. ${ }^{9}$ All three previously reported imipramine associated or "provoked" pheochromocytoma crises were hypertensive. A patient is reported who developed severe cardiogenic shock after taking imipramine and was subsequently discovered to have a pheochromocytoma causing catecholamine-induced dilated cardiomyopathy. No similar cases were found in an extensive review of the literature.

From the Department of Surgery, University of Michigan Medical Center, Ann Arbor, MI

Manuscript received March 26, 1993; revision accepted October 11, 1993.

Address reprint requests to Dr Ferguson, UH B1C255/0014, 1500 E Medical Center Dr, Ann Arbor, MI 48109-0014.

Key Words: Cardiomyopathy, catecholamines, imipramine, pheochromocytoma.

Copyright (C) 1994 by W.B. Saunders Company

0735-6757/94/1202-0016\$5.00/0

\section{CASE REPORT}

A 35-year-old white man presented to the emergency department (ED) with a chief complaint of chest discomfort and shortness of breath. He had been seen in the ED on several occasions for intermittent palpitations associated with nausea during the preceding 5 months and had been admitted once to rule-out myocardial infarction. His outpatient evaluation had included a Holter monitor, chemistry profile, and thyroid function tests all of which were normal. The patient reported a 5 to 10 pound weight loss over the previous year as a result of a weight and cholesterol reduction regimen that consisted of diet and exercise. His family history was significant only for coronary artery disease. He quit smoking 15 years previously. drank occasionally, and denied intravenous drug use or gay lifestyle. He had been seen by a neurologist for headaches 2 days before presentation and was prescribed imipramine (dosage unknown); the patient reported taking two doses.

On presentation, the patient had central cyanosis and tachypnea. He was placed on a cardiac monitor and administered oxygen. Initial vital signs were blood pressure, $54 \mathrm{~mm} \mathrm{Hg}$ by doppler; pulse, 140 beats $/ \mathrm{min}$; respirations 40 breaths/min; and rectal temperature, $33^{\circ} \mathrm{C}$. He was awake, alert, and oriented with normal speech, a clear sensorium, and an affect that was appropriately anxious given his distress. Pupils were $10 \mathrm{~mm}$ bilaterally and minimally reactive. The optic discs were flat, and there were no abnormal retinal findings. The rest of the head and neck examination was normal. Cardiac auscultation showed distant cardiac sounds, a regular tachycardia of 140 , normal S1, and S2, and a grade II systolic murmur at the left sternal border and no visible jugular venous pulsations. Lung fields had rales bilaterally. The abdomen was soft and nontender without organomegaly; the extremities were normal except for the cyanosis. Neurologically, the patient demonstrated diffuse weakness but no focal motor, sensory, or cranial nerve deficits.

A chest $x$-ray showed bilateral diffuse reticular infiltrates with a ground glass appearance. Electrocardiogram was interpreted as sinus tachycardia with normal intervals and axis, no acute ischemic or infarction pattern evident, and no evidence of left ventricular hypertrophy.

Complete blood cell count showed a white blood cell level of 27.5 $\mathrm{K} / \mathrm{mL}$ with $75 \%$ segmented neutrophils, $9 \%$ bands, $10 \%$ lymphocytes, $3 \%$ monocytes, $3 \%$ atypical lymphocytes. Hemoglobin was $18.1 \mathrm{~g} / \mathrm{dL}$ and hematocrit $52.6 \%$. Serum analysis was $\mathrm{Na}^{+}, 146 \mathrm{mEq} /$ $\mathrm{dL} ; \mathrm{K}^{+}, 4.2 \mathrm{mEq} / \mathrm{dL} ; \mathrm{Cl}^{-}, 104 \mathrm{mEq} / \mathrm{dL} ; \mathrm{HCO}^{-}, 20 \mathrm{mEq} / \mathrm{dL}$; blood urea nitrogen, $19 \mathrm{mg} / \mathrm{dL}$; creatinine, $2.8 \mathrm{mg} / \mathrm{dL}$; Glucose, 94 $\mathrm{mg} / \mathrm{dL}: \mathrm{Ca}^{+2}, 7.5 \mathrm{mEq} / \mathrm{dL} ; \mathrm{PO}^{-2}, 6.7 \mathrm{mEq} / \mathrm{dL}$; and amylase 520 $\mathrm{mg} / \mathrm{dL}$. Toxicology screen was negative for acetaminophen, amphetamines, cocaine, and salicylates. Blood and urine cultures and Legionella titers were sent to the laboratory also.

Despite increasing, $\mathrm{FiO}^{2}$ the patient's hypoxemia worsened and his blood gas analysis on $100 \% \mathrm{O}^{2}$ by non-rebreather mask showed $\mathrm{pH}, 7.20 ; \mathrm{PCO}_{2}, 44$ torr; $\mathrm{PO}_{2}, 43$ torr; base deficit, 11 and $\mathrm{O}_{2}$ saturation, 68\%; carboxyhemoglobin 0.4 torr. At this point, the patient was electively intubated. With a tidal volume of $900 \mathrm{~mL}$, IMV rate of $13,40 \% \mathrm{FiO}_{2}$, and positive end-expiratory pressure (PEEP) of +14 , repeat arterial blood gas analysis showed $\mathrm{pH}$ of $7.44, \mathrm{PCO}_{2}$ of 32 torr. $\mathrm{Po}_{2}$ of 72 torr, base deficit of 1 , and $\mathrm{O}_{2}$ saturation of $95 \%$. 
The patient was given $2 \mathrm{~L}$ of isotonic intravenous solution that increased the blood pressure to $84 \mathrm{~mm} \mathrm{Hg}$ by palpation. He was begun on a dopamine drip at $12 \mu \mathrm{g} / \mathrm{kg} / \mathrm{min}$, with continued fluid loading, but the systolic pressures remained in the $80 \mathrm{~s}$.

The patient was admitted to the intensive care unit where a pulmonary artery catheter was placed. After approximately $4.5 \mathrm{~L}$ of crystalloid had been administered, initial hemodynamic data showed pulmonary arterial pressure (PAP), 30/15 torr $(\mathrm{nl}=30-60 / 10-20)$; pulmonary artery occlusion pressure (wedge), 16 torr $(\mathrm{nl}=10-18)$; cardiac index, $1.8 \mathrm{~L} / \mathrm{min} / \mathrm{m}^{2}(\mathrm{nl}=3.0$ to 5.0$)$; systemic vascular resistance index, 2,624 dynes $/ \mathrm{s} / \mathrm{cm}^{5} / \mathrm{m}^{2}(1,800$ to 2,500$)$; and pulmonary vascular resistance index, 644 dynes $/ \mathrm{s} / \mathrm{cm}^{5} / \mathrm{m}^{2}$ (50 to 220 ). Emergency echocardiography showed a moderately dilated left ventricle, with markedly decreased function and global hypokinesis and an estimated ejection fraction of $25 \%$. There were no segmental wall motion abnormalities. The right ventricle was small with no intraluminal masses. The patient was continued on dopamine.

He was begun on broad spectrum antibiotics including coverage for Legionella, Pneumocystis carinii, and Mycoplasma. The following morning an abdominal ultrasound was performed to follow-up the hyperamylasemia. This showed normal pancreas, gallbladder, and kidneys and a right suprarenal mass. Computerized tomography of the abdomen showed the right suprarenal mass to be solid. Urine vanillyimandelic acid total returned $11.2 \mathrm{mg} / 24$ hours ( $\mathrm{nl}, 2.2$ to 10 ) and urine metanephrines totaled, $2.5 \mathrm{mg} / 24$ hours ( $\mathrm{nl}<0.9$ ). Fractionated total plasma norepinephrine and epinephrine levels were reported as $20,000 \mathrm{pg} / \mathrm{mL}$ (nl, 110 to $410 \mathrm{pg} / \mathrm{mL}$ ) and $11,000 \mathrm{pg} / \mathrm{mL}$ ( $\mathrm{nl}<50 \mathrm{pg} / \mathrm{mL}$ ), respectively, confirming the diagnosis of pheochromocytoma. The patient was started on $\alpha$-blockade with phenoxybenzamine and continued on intravenous hydration.

On hospital day 3 , the patient's pulmonary function had improved and he was extubated uneventfully. A repeat echocardiogram on hospital day 11 showed improved left ventricular function. The patient had a ${ }^{131} \mathrm{I}$-meta-iodobenzylguanidine (I-MIBG) scan performed that detected no other foci of pheochromocytoma. During the next week, the patient was treated presumptively for pneumonia and was administered intravenous fluids to expand vascular volume. He was taken to the operating room on the 19th hospital day for resection of his pheochromocytoma. The postoperative course was uneventful and the patient was discharged 10 days later.

\section{DISCUSSION}

Imipramine is a tricyclic antidepressant used for treatment of endogenous depression, urinary incontinence, and some headaches. It blocks the postsynaptic reuptake of neurotransmitters, among them norepinephrine, in the peripheral and central nervous systems, thus increasing levels in the synaptic cleft. Infusions of norepinephrine have a markedly increased pressor response in the presence of some tricyclic antidepressants. ${ }^{9}$

Pheochromocytoma is a catecholamine producing tumor of chromaffin cells usually in the adrenal medulla, which produces symptoms of adrenergic hyperactivity. The cell line arises from neural crest cells. Although the tumors usually produce primarily norepinephrine with smaller amounts of epinephrine, rarely epinephrine may predominate and most tumors produce both. Pheochromocytoma can be a part of multiple endocrine neoplasia syndromes; $90 \%$ are histologically benign. ${ }^{16}$ Typical signs and symptoms include hypertension and its consequences, palpitations, or headaches. The excess catecholamines can precipitate angina and cerebrovascular accidents. ${ }^{15}$ The diagnosis of pheochromocytoma requires a high index of suspicion. The classic pre- sentation of a pheochromocytoma is the triad of headache, diaphoresis, and palpitations in an acutely hypertensive patient. However, this triad is neither common nor specific to the presentation of a pheochromocytoma. The most common finding is hypertension, which may be paroxysmal or sustained with superimposed paroxysms. ${ }^{17}$ Other typical complaints are tachycardia, flushing, diaphoresis, postural hypotension, headache, tremor, angina, vertigo, a sense of impending doom, weight loss, and agitation. ${ }^{16}$

Routine laboratory analysis can be normal or can show hyperglycemia and/or glycosuria. Once the diagnosis is entertained, spot urine metanephrine measurement is a satisfactory initial screen for patients with a history suggestive of pheochromocytoma crisis; it is sensitive, convenient for patient and physician, and relatively inexpensive. If the results are positive, a 24-hour urine sample should be collected for metanephrines, vanillylmandelic acid and unconjugated catecholamines, all of which will be elevated in patients with pheochromocytoma. Some laboratories now offer direct plasma level measurement of catecholamines. ${ }^{17}$

Once the diagnosis is established, the hypertensive patient's blood pressure is best controlled by $\alpha$-blockade with phenoxybenzamine, $1 \mathrm{mg}$ IVP followed by a drip of $20 \mathrm{mg}$ in $500 \mathrm{~mL} \mathrm{D} 5 \mathrm{~W}$ titrated to patient's blood pressure. Alternative titration with nitroprusside is also effective. Volume expansion while titrating will assist in controlling wide swings in blood pressure. The most serious adverse effects are tachycardia, atrial, and ventricular arrhythmias. These are treated with $\beta$-blockade after $\alpha$-blockade has been established. ${ }^{15}$ Propranolol should be given intravenously at $1 \mathrm{mg} / \mathrm{min}$ until response is obtained, then every 4 hours. $\beta$-blockers should not be used as the primary treatment of hypertension because blockade of $\beta$-mediated vasodilation will lead to unopposed $\alpha$-mediated vasoconstriction and severely increased hypertension. ${ }^{15}$ If the patient is not judged to be a surgical candidate, symptomatic treatment with $\alpha$-blockade is usually therapeutic. ${ }^{15}$ Radio ablation with ${ }^{131}$ I-MIBG is palliative option in patients with metastatic disease or who are otherwise not surgical candidates. ${ }^{18}$ The preferred treatment is surgical resection. Chronic high levels of norepinephrine will lead to persistently increased vascular tone. The high vascular tone and the effects of the catecholamines on the renin-angiotensin-aldosterone axis will produce volume contraction and hypovolemia. Volume expansion during a 2-to 3-week period should precede surgery. ${ }^{131} \mathrm{I}$-MIBG scanning is performed to detect any other foci of tumor. Surgical resection is virtually $100 \%$ curative for benign tumors. ${ }^{17}$

Reversible catecholamine-induced cardiomyopathy has been reported on several occasions as a rare consequence of pheochromocytoma. Both dilated and hypertrophic cardiomyopathies have been associated with catecholamine toxicity. In a report of serial echocardiograms, Lam et al showed regression of both hypertrophy and dilatation and improved ejection fraction after surgical removal of a pheochromocytoma. ${ }^{7}$ Endocardial biopsy shows a mild focal lymphocytic infiltration with little myocytolysis. Most echocardiographic and histological studies demonstrate global disease. Van Vliet, Burchel and Titus found catecholamine-induced myocarditis to be associated with increased fibrous tissue and hypertrophy in more than $50 \%$ of patients dying with a 
pheochromocytomas. They also reported focal myocarditis associated with pheochromocytoma. ${ }^{1}$

Several theories have been suggested on the pathophysiology of catecholamine-induced cardiomyopathy. There is a reduced inotropic sensitivity to noradrenalin suggesting down regulation of receptors. Vasospasm leading to cellular hypoxia, and damage by free radicals have also been proposed. However, the findings of both clinical and biochemical investigations suggests $\mathrm{Ca}^{2+}$ plays a key role in the development of catecholamine-induced cardiomyopathy. ${ }^{10,11,12,14}$ In a rat model of induced catecholamine cardiotoxicity, Makino et al reported several key findings. Electron microscopy showed contracted sarcomeres and swelling of the mitochondria. They also showed depression of the sarcolemmal $\mathrm{Na}^{+}$-dependent $\mathrm{Ca}^{2+}$ uptake activity within 3 hours of exogenous catecholamine injection and intracellular $\mathrm{Ca}^{2+}$ overload. ${ }^{11}$ In 1983 , Serfas et al reported a patient with pheochromocytoma and hypertrophic cardiomyopathy and successful treatment with a $\mathrm{Ca}^{2+}$ channel blocker. Their patient had complete relief from hypertension, angina, diaphoresis, and dyspnea with nifedipine treatment and immediate return of symptoms when changed to placebo. Although the entire syndrome of catecholamine-induced cardiomyopathy is probably multifactorial, receptormediated intracellular $\mathrm{Ca}^{2+}$ metabolism seems to be the primary biochemical abnormality.

A review of the English language literature produced only three similar reports of imipramine-induced pheochromocytoma crisis. Mok and Swann first reported an imipramine provoked pheochromocytoma crisis in August, 1978. The case was an 11-year-old girl admitted with profuse sweating, tachycardia, and hypertension after a dose of imipramine. ${ }^{1}$ Five months later, Johnson et al reported a similarly diagnosed pheochromocytoma in an adult. ${ }^{2}$ The only other report found is from Birkebaek and Perrild in 1986. ${ }^{3}$ A 14-yearold boy who was being treated with imipramine for enuresis developed hypertension and tachycardia, and was subse quently diagnosed with a pheochromocytoma. No other case of cardiogenic shock associated with pheochromocytoma and imipramine was identified.

Why the patient presented here did not show the enhanced pressor response to the imipramine is difficult to state with certainty. The patient's minimal response to $\beta$-adrenergic doses of dopamine, as well as echocardiographic and electrocardiogram evidence support the existence of a dilated cardiomyopathy. Also, the patient was hypovolemic, as evidenced by his response to fluids and his initial PAPs. Perhaps intravascular volume had been contracted to its limit and therefore further vasoconstriction even with the imipramine effect produced no changes in blood pressure. Another possibility is that the imipramine did produce an acute accumulation of noradrenalin and a subsequent "surge" of the intracellular $\mathrm{Ca}^{2+}$ as opposed to the chronic accumulation of $\mathrm{Ca}^{2+}$ before imipramine therapy. In this way the imipramine could have accelerated the disease process by causing a massive increase in intracellular $\mathrm{Ca}^{2+}$.

\section{SUMMARY}

A patient presented to the emergency department in cardiogenic shock after recently beginning therapy with imipra- mine. The patient had catecholamine cardiomyopathy caused by a pheochromocytoma that resolved after surgical resection. A literature search found three previously reported cases of imipramine-associated pheochromocytoma crisis, all of which had hypertensive presentations. Pheochromocytoma crisis is an infrequent cause of hypertension, a rare cause of cardiogenic shock, and has on only a few occasions been discovered as the result of a drug reaction. An association between imipramine, pheochromocytoma, and cardiogenic shock has not been previously described.

\section{REFERENCES}

1. Mok J, Swann I: Diagnosis of pheochromocytoma after ingestion of imipramine. Arch Dis Child 1978;53(8):676-677

2. Johnson ER, Jones MD, Stewart JN: Occurrence of a pheochromocytoma after ingestion of imipramine. J Am Osteop Assoc 1979;78(5):332-335

3. Birkebaek NH, Perrild BD: Pheochromocytoma diagnosed in an enuertic boy after imipramine-induced hypertension. Ped Hemat-Oncol 1986;3(3):203-205

4. Sadowski D, Cujec B, McMeekin JD, et al: Reversibility of catecholamine-induced cardiomyopathy in a woman with pheochromocytoma. Can Med Assoc J 1989;141(9):823-824

5. Imperato-NcGinley J, Gautier T, Ehlers K, et al: Reversibility of catecholamine-induced dilated cardiomyopathy in a child with pheochromocytoma. N Engl J Med 1987;316(13):793-797

6. Van Vliet PD, Burchel HB, Titus JL: Focal myocarditis associated with pheochromocytoma. N Engl J Med 1966;274:11021108

7. Lam JB, Shub C, Sheps SG: Reversible dilatation of hypertrophied left ventricle in pheochromocytoma: serial twodimensional echocardiographic observations. Am Heart $\mathrm{J}$ 1985;109(3 Pt 1):613-615

8. Sardesai SH, Mourant AJ, Sivathandon Y, et al: Phaeochromocytoma and catecholamine induced cardiomyopathy presenting as heart failure. Br Heat $J$ 1990;63(4):234-237

9. Ellenhorn MJ, Barceloux DG: Medical Toxicology: Diagnosis and Treatment of Human Poisoning. New York, NY, Elsevier, 1988, pp 402-415

10. Alpert LI, Pai SH, Zak FG, et al: Cardiomyopathy associated with a pheochromocytoma. Report of a case with ultrastructural examination of the myocardial lesions. Arch Pathol 1972;93(6):544-548

11. Makino N, Dhruvarajan R, Elimban V, et al: Alterations of sarcolemmal $\mathrm{NA}^{+}-\mathrm{Ca}^{2+}$ exchange in catecholamine-induced cardiomyopathy. Can J Cardiol 1985;1(3):225-232

12. Serfas D, Shoback DM, Lorell BH: Phaeochromocytoma and hypertrophic cardiomyopathy: Apparent suppression of symptoms and noradrenaline secretion by calcium-channel blockade. Lancet $1983 ; 2(8352): 711-713$

13. Frustaci A, Loperfido F, Gentiloni N, et al: Catecholamineinduced cardiomyopathy in multiple endocrine neoplasia. A histologic, ultrastructural, and biochemical study [see comments] Chest $1991 ; 99(2): 382-385$

14. Russo MA, Cittadini $A$, Dani $A M$, et al: An ultrastructural study of calcium-induced degenerative changes in dissociated heart cells. $J$ Mol Cell Cardiol 1982;13:265-279

15. Isselbacher K, Adarns R, Petersdorf R, et al: Harrison's Principles of Internal Medicine, ed 9. New York, NY, McGrawHill, 1980, pp 1737-1741

16. Robbins $S$, Cotran R: Pathologic Basis of Disease. Philadelphia, PA, Saunders, 1979, pp 402-1404

17. Greenfield L, Mulholland M, Oldham K, et al: Surgery: Scientific Principles and Practice. Philadelphia, PA, Lippincott, 1993, pp 1209-1224

18. Geatti $O$, Shapiro B, Virgolini L: Late presentation of metastatic pheochromocytoma: A problem case solved by $1-131$ MIBG scintigraphy. Clin Nucl Med 1990;15(2):101-104 